\title{
Estimating the agreement between the metabolic rate calculated from prediction equations and from a portable indirect calorimetry device: an effort to develop a new equation for predicting resting metabolic rate
}

Eleni Pavlidou' ${ }^{1}$ Dimitris Petridis ${ }^{2}$, Maria Tolia ${ }^{3 *}$, Nikolaos Tsoukalas ${ }^{4}$, Antigoni Poultsidi $^{5}$, Aristeidis Fasoulas ${ }^{1}$, George Kyrgias ${ }^{3}$ and Constantinos Giaginis ${ }^{1^{*}}$

\begin{abstract}
Background: Many studies have been performed over time in order to determine the reliability of metabolic rate prediction equations.

Purpose: To evaluate the agreement, in terms of bias, absolute bias and accuracy between metabolic rate prediction equations and measured metabolic rate using indirect calorimetry system (IC), investigating also the factors affecting this agreement.

Methods: The anthropometric features of 383 Caucasian participants of all Body Mass Index (BMI) classes were recorded and Resting Metabolic Rate (RMR) was measured by using the IC Fitmate portable device. The resulting values were compared with the predictive values of Harris \& Benedict, Schofield, Owen, FAO-WHO-UNU, Mifflin and Harrington equations.

Results: A closer approximation in agreement was obtained using the Harrington equation (based on BMl, age and gender). The equations using variables, such as weight, height, age and gender demonstrated higher agreement than the equations using merely weight and gender. Higher educational level was associated with normal weight, while higher calorific ratio was found in the class of normal-weighted individuals. An inverse relationship between BMI and RMR was also observed and a logarithmic equation for calculating RMR was created, which was differentiated in relation to $\mathrm{BMI}$ classes, using the weight and gender variables.

Conclusion: A better measurement agreement between RMR prediction equations and IC may be achieved due to BMl consideration. The present findings contributed to a better understanding of the measured parameters, confirming the inverse relationship between BMI and RMR. Age group and gender variables may also exert significant role on the bias response of some RMR equations.
\end{abstract}

Keywords: Basal metabolic rate, Indirect calorimetry, Predictive equation, Resting energy expenditure, Resting metabolic rate

\footnotetext{
*Correspondence: mariatolia@med.uth.gr; cgiaginis@aegean.gr

${ }^{3}$ Department of Radiotherapy, School of Health Sciences, Faculty of

Medicine, University of Thessaly, 41110 Biopolis, Larissa, Greece

'Department of Food Science and Nutrition, University of Aegean, Mitropoliti

loakim 2, Myrina, Lemnos, 81440 Athens, Greece

Full list of author information is available at the end of the article
}

(c) The Author(s). 2018 Open Access This article is distributed under the terms of the Creative Commons Attribution 4.0 International License (http://creativecommons.org/licenses/by/4.0/), which permits unrestricted use, distribution, and reproduction in any medium, provided you give appropriate credit to the original author(s) and the source, provide a link to the Creative Commons license, and indicate if changes were made. The Creative Commons Public Domain Dedication waiver (http://creativecommons.org/publicdomain/zero/1.0/) applies to the data made available in this article, unless otherwise stated. 


\section{Background}

Metabolic rate is the rate of energy expenditure in humans. The highest amount of this energy (50-75\%) is essential for the development and maintenance of basic organic functions, while the person is at rest. Terms such as Basal Metabolic Rate (BMR) [1-4] or Resting Metabolic Rate (RMR) [5, 2] are used to define this energy expenditure and are often confused with each other, although they vary by approximately 10\%. Basal Energy Expenditure (BEE) [6, 7] and Resting Energy Expenditure (REE) $[8,9]$ were derived from the conversion of BMR and RMR to kcal or kj /24 h. Several equations have been developed to calculate BMR and RMR, taking into account basic individual characteristics such as weight, height, age, gender etc., while they are measured using various methods of direct or indirect calorimetry (IC), or even using non-calorimetric methods. The rest of metabolic rate is the amount of energy expended for the individual's physical activity and is expressed as Total Energy Expenditure (TEE). TEE is the sum of BMR or RMR, taking also into account physical activity or exercise (20-40\%), Thermic Effect of Food (TEF) which ranges between 5 and $30 \%$ and sometimes adaptive thermogenesis or/and Stress [9, 10].

In the present study, RMR was measured by using the IC Fitmate portable device, which is a functional solution in clinical and non-clinical environment. The reliability and quality aspect of this device has been investigated by a series of studies [11-13] and has been used in research to determine energy intake for various populations $[14,15]$. However, the fact that these measuring devices are not always available necessitates the use of appropriate prediction equations, which are considered a useful tool for the calculation of metabolic rate. Several studies have investigated the reliability of prediction equations [16-18], as well as the factors that likely affect the body's metabolic rate $[19,20]$ and thereafter the use of those factors for more accurate determination.

In view of the above considerations, the purpose of the present study was to evaluate the potential agreement in accuracy and absolute bias between prediction equations and measured values via the use of an IC device, to determine potential factors that affect the predictability of the equations and to create a new equation that may better respond to the study population.

\section{Study population and methods Study population}

Data (Table 1) from 383 Caucasians participants were used in this study (men $n=105$ and women $n=278$ ), age 10-77 years old (mean: $37.5 \pm 14.4$ years old), Body Mass Index (BMI) $16.6-60.2 \mathrm{Kg} / \mathrm{m}^{2}$ (mean: $30.5 \mathrm{Kg} / \mathrm{m}^{2}$ $\pm 7.5 \mathrm{Kg} / \mathrm{m}^{2}$ ), weight range: $42.7-177 \mathrm{Kg}$ (mean: $85.3 \mathrm{Kg}$
Table 1 Descriptive statistics of measured metabolic rates according to anthropometric factors of the subjects $(n=383)$ Mean \pm St.Dev (Lowest- Highest value)

\begin{tabular}{lll}
\hline & Male & Female \\
\hline Age & $37.5 \pm 15(10-77)$ & $37.5 \pm 14(12-76)$ \\
BMI $^{\mathrm{a}}$ & $32.0 \pm 6.9(16.6-57.8)$ & $29.8 \pm 7.6(17.3-60.2)$ \\
Weight & $100.1 \pm 23.1(59-177)$ & $79.7 \pm 20(42.7-166)$ \\
Height & $1.76 \pm 0.08(1.44-1.98)$ & $1.63 \pm 0.06(1.48-1.86)$ \\
\hline
\end{tabular}

${ }^{\mathrm{a}} \mathrm{RMRm}$ means and their $95 \%$ confidence intervals in the BMI classes ( $\mathrm{kcal} / \mathrm{kg}$ body weight/day)

$\pm 23.2 \mathrm{Kg}$ ) and height range from 1.44 up to $1.98 \mathrm{~m}$ (mean: $1.67 \mathrm{~m} \pm 0.09 \mathrm{~m}$ ). A few groups of participants were missing from the whole sample (Additional file 1: Table S1 AF): women $>60$ years old in the normal weight class and men of age groups $10-18$ and $>60$ years old in the obese class II. Moreover, the under-weight class was not included in the statistical analysis due to the particularly low number of under-weight people in the sample $(n=3)$.

\section{REv1 sampling size}

The sampling procedure followed the recording of first-time incomers that randomly or by date visited the laboratory so creating a physical succession of sampling numbers (identifications). A prospective study with the first 150 incomers showed reasonable results for the percentage deviation of RMR measured (RMRm) from RMR estimated (RMRe) but not for the statistics purposed for the breakdowns of physical variables. Therefore, we decided to over-double the sampling size for safety reasons.

\section{Methods}

The anthropometric features were recorded, RMRm was read and RMRe was calculated by using Harris \& Benedict (H-B) [21], H-B Rev. by Roza \& Shizgal [22], H-B Abbreviated [23], Schofield [24], Owen [25], FAO-WHO-UNU (F-W-U) [26], Mifflin [27] and Harrington [28] prediction equations (Additional file 2: Table S1 AF) Prediction equations were grouped into 5 categories depending on the parameters they included (Additional file 2: Table S1 AF):

Category 1 - weight, height, age and gender (HB, HB Rev., Mifflin),

Category 2- weight, height, age group and gender (FWU),

Category 3- weight, gender and age group (FWU (2) and Schofield),

Category 4- weight and gender (Owen and HB Abbreviated).

Category 5- BMI, age and gender (Harrington). 
All measurements were performed by a trained and certified nutritionist-dietitian under standard protocol. Body weight was measured and recorded by weight grading of $0.1 \mathrm{~kg}$ using Tanita fat monitor wearing no shoes and clothes. Height was measured by using the Seca height meter under standard protocol (no shoes, straight torso, having the buttocks, shoulders and head touching the vertical surface of the wall and looking horizontally). BMI was calculated in $\mathrm{kg}$ divided by the square of the height in $\mathrm{m}$ and the grouping was performed according to World Health Organizations guidelines. RMR was measured by using the indirect calorimeter Fitmate Pro (Cosmed), with silicone face mask, certified by Gold Standards. Scientific evidence indicates that in a steady state RQ is always in the range of $0.84 \pm 0.04$. Fitmate measures oxygen consumption Oxygen uptake (VO2), and gets a fixed breathing rate (RQ), which is set to 0.85 by default or can be set by the user. The measurement was performed after an overnight fast, absence of disease or infection and the least emotional disturbances within a quite environment (absence of noise) concerning people with normal nutritional status. Participants were requested not to engage in physical activity for $24 \mathrm{~h}$, smoke, have coffee or stimulants for $12 \mathrm{~h}$ before the examination. Participants were also requested to lie on a mattress in the supine position for $20 \mathrm{~min}$. The measurement was carried out for $12 \mathrm{~min}$ in a thermally neutral environment $\left(22^{\circ} \mathrm{C}\right.$ up to $25^{\circ} \mathrm{C}$ ). The first $5 \mathrm{~min}$ of the measurement were skipped and were used for the last $7 \mathrm{~min}$ [9].

\section{Statistical analysis}

RMRm data were compared with the corresponding values calculated from RMRe, according to the formula $\mid$ mean(RMRm) - mean(RMRe)|, hence called absolute bias [29]. Percentage deviation of the estimated values (known as accuracy) was expressed as the absolute bias divided by mean(RMRe) and multiplied by 100 .
Percentage deviation of RMRm values was calculated in a similar manner (absolute bias divided by mean (RMRm) times 100). Higher values indicate lower accuracy and generally deviations less than $10 \%$ are indicative of adequate accuracy. Absolute biases of RMR (individual values) were examined against BMI classes, age groups and gender, using multiple regression analysis and backward elimination of variables importance. All absolute biases were transformed aiming to follow the normal distribution using $\lambda$ transformed coefficients, which ranged between 0.34 and 0.41 (zone of $\operatorname{logx}$ and $\sqrt{\mathrm{X}}$ ). The physical characteristics expressed by age groups, gender and education level where cross-tabulated with BMI classes, using the Pearson's chi square test of variable independence. Statistically significant differences were checked employing the standardized residuals (st. res). Values greater than $|2|$ indicate significant effect. A regression equation was attempted between the dependent RMR of IC and the independent BMI-classes as literature indicates such relationship to hold [20,30,31]. All statistical analyses were performed by Minitab 17 statistical software (Minitab Inc., Pennsylvania, USA).

\section{Results}

The comparisons between RMRm records with those of prediction equations are shown in Table 2. In all cases, the $95 \%$ confidence intervals of mean biases do not include zero, meant that there is not statistically significant agreement between the IC RMRm and the calculated RMRe. It should be kept in mind, however, that a close approximation towards a reasonable agreement is under consolidation after consulting the lower confidence intervals of biases of nearly all the equations concerned. This trend can be further improved by increasing the sample size and taking in parallel into account the effects of gender and age groups on the formation of the equations. The percentage deviation of either RMRm or

Table 2 Descriptive statistics and further relationships between RMRm (with IC) and RMRe

\begin{tabular}{|c|c|c|c|c|c|c|c|c|c|}
\hline & Equation & Min & Max & Mean & St.dev & Mean bias & $95 \% \mathrm{Cl}$ of bias & RMRm\% & $\mathrm{N}$ \\
\hline & RMRm & 717 & 3189 & 1591 & 457.8 & & & & \\
\hline \multirow[t]{3}{*}{ Weight (wt), Height (ht), Age and Gender } & $\mathrm{H}-\mathrm{B}$ & 1227 & 3227 & 1687 & 340.0 & +96 & $62.2-129.3$ & $6.0 \%$ & 149 \\
\hline & $\mathrm{H}-\mathrm{B}(\mathrm{Rev})$ & 1213 & 3183 & 1678 & 338 & +83 & $54.0-121.6$ & $5.2 \%$ & 143 \\
\hline & Mifflin & 1242 & 2769 & 1718 & 260 & +127 & $91.8-162.8$ & $8.0 \%$ & 129 \\
\hline Wt, Ht, Age Groups and Gender & F-W-U (1) & 1124 & 3387 & 1849 & 571 & +258 & $211.0-305.3$ & $16.2 \%$ & 125 \\
\hline \multirow[t]{2}{*}{ Wt, Gender and Age Groups } & F-W-U (2) & 1124 & 3362 & 1695 & 336 & +105 & 70.9-138.2 & $6.6 \%$ & 145 \\
\hline & Schofield & 1119 & 3364 & 1688 & 344 & +97 & $62.0-132.3$ & $6.1 \%$ & 139 \\
\hline \multirow[t]{2}{*}{ Wt, Age and Gender } & Owen & 1102 & 2684 & 1509 & 291 & -82 & $-115.8--47.6$ & $5.1 \%$ & 131 \\
\hline & $\mathrm{H}-\mathrm{B}(\mathrm{Abbr})$ & 973 & 4248 & 1979 & 560 & +388 & $343.5-432.8$ & $24.4 \%$ & 93 \\
\hline BMI, Age and Gender & Harrington & 1166 & 2775 & 1627 & 283 & +37 & $2.0-71.2$ & $2.3 \%$ & 153 \\
\hline
\end{tabular}


RMRe was lower than the widely accepted $10 \%$ in 7 out or 9 equations Table 2. Harrington's equation was found the most reliable according to the records of this study (2.3 and $2.2 \%$ correspondingly) while eqs. F-W-U (1) and $\mathrm{H}-\mathrm{B}$ (Abbr) were the least acceptable.

The lowest bias and in close agreement was obtained using Harrington's formula, based on BMI, age and gender $(+37$ units of deviation, CI range $=2.0-71.2)$ and the highest by H-B Abbreviation's formula based on weight and gender $(+388 \mathrm{Kcal})$. All deviations were overestimated (positive values) except for Owen's formula ( -82 units, $5.1 \%$ accuracy) and ranged between -82 and $+388 \mathrm{Kcal} /$ day.

Multiple regression analysis demonstrated that absolute bias responses are affected by only 4 prediction equations (Table 3): BMI by H-B Abbreviation, Owen and loosely by Schofield, Gender by F-W-U (2) and fairly by Owen, age group by F-W-U (2) equation. The effects are best elucidated in Fig. 1 in which, primarily, BMI increases the absolute bias with class increase, in particular, from obesity I and upwards. This increasing trend of bias response is smoothly depicted in the H-B Abbreviation equation along with all BMI classes, approaching a high magnitude of difference of 600 units (800-200). Males respond more vigorously in bias using F-W-U (2) equation than Owen's. In the latter, the bias response steadily increases with age group after the point individuals reaching the age of 30-45 years old.

Statistically significant effects (dependencies) were found between BMI classes and gender, age groups and education level (Additional file 3: Table S3 AF). Males with normal weight are encountered less frequently than should be (st. res $=-2.74$ ) and more frequently those with severe obesity (st. res $=+2.12$ ). As for age groups, normal weight is rare for elders $(>60$, st. res $=-2.14$ ) and, interestingly, young people aged 10-18 appear more frequently severely obese (st. res $=+2.84$ ) as also elders do so (st. res $=+2.12$ ) while the group 19-30 years old occurs less frequently in the same class. Highly educated people (tertiary class) are encountered in higher numbers than expected when they cross-tabulate with normal weight (st. res $=+2.03$ ).

BMI classes and estimated RMRm were further examined for linear trend using regression analysis after logarithmic

Table 3 Regression effects of gender, BMI and age on the absolute bias response

\begin{tabular}{lllll}
\hline$\lambda$ & Bias response & Gender & BMl & Age-group \\
\hline 0.41 & H-B Abbreviation & & $<0.001$ & \\
0.41 & Owen & 0.036 & $<0.001$ & \\
0.38 & Schofield & & 0.023 & \\
0.34 & F-W-U (2) & $<0.001$ & & 0.023 \\
\hline
\end{tabular}

The coefficient $\lambda$ refers to optimal data transformation which approximates the square root transformation in order to conform to normal prerequisites (Fig. 2a). RMRm response declines linearly with body weight increase, starting from $21.7 \mathrm{Kcal} / \mathrm{KgBW} /$ day and ending down to $17.0 \mathrm{Kcal} / \mathrm{KgBW} /$ day (Table 4). Explicitly, more calories per $\mathrm{Kg} / \mathrm{BW}$ are consumed by normal-weighted individuals than those belonging to higher BMI classes. Moreover, the decline is statistically significant between normal-weighted and over-weighted classes as indicated by the non-overlapping confidence limits (Table 4). The optimal regression line is described by the logarithmic (power) equation:

$$
\operatorname{RMR}(\mathrm{Kcal} / \mathrm{KgBW} / 24 \mathrm{~h})=21.53 \times(\mathrm{BMI})^{-0.152}\left(\mathrm{R}^{2}=98.9 \%\right)
$$

or in linear form:

$$
\log _{10}(\mathrm{RMR})=1.333-0.1522 \times \log _{10}(\mathrm{BMI})
$$

The above equation explains that an increase of BMI by 1 class causes a decrease of RMR equal to $0.1522 \mathrm{Kcal} / \mathrm{KgBW} /$ day.

The above equation can be further expanded by separating the gender into males (Fig. 2b):

$$
\begin{aligned}
\mathbf{R M R}_{\text {males }}(\mathbf{K c a l} / \mathbf{K g ~ B W} / \mathbf{2 4} \mathbf{h}) & =25.41 \times(\mathrm{BMI})^{-0.2115}\left(\mathbf{R}^{2}=91.9 \%\right) \\
\text { and } \log _{10}\left(\mathrm{RMR}_{\text {males }}\right) & =1.405-0.2115 \times \log _{10}(\mathrm{BMI})
\end{aligned}
$$

and females (Fig. 2b):

$$
\begin{aligned}
\mathbf{R M R}_{\text {females }}(\mathbf{K c a l} / \mathbf{K g ~ B W} / \mathbf{2 4 h}) & =21.09 \times(\mathrm{BMI})^{-0.1786}\left(\mathbf{R}^{2}=97.8 \%\right) \\
\text { and } \log _{10}\left(\mathrm{RMR}_{\text {females }}\right) & =1.324-0.1786 \times \log _{10}(\mathrm{BMI})
\end{aligned}
$$

The configuration/formation of the above equations is depicted in Table 5.

\section{Discussion}

The design of this study and the determination of agreement between RMRm and RMRe was partly based on the methodology proposed by Michels, 2010 [29]. The present study compared the prediction equations based on particular factors that they use (weight, height, age, gender, BMI) and examined the predictive reliability of their responses. More specifically, the study supports findings of previous works that have shown that the use of BMI, which includes all the tissues of the body (via the use of weight divided by the square of height), renders the equations more reliable [20,31]. The current study also supports previous findings, according to which characteristics such as gender, age, height and body weight are correlated with metabolic rate. These characteristics can easily be recorded and their significant effect on the reliability of equations has been indicated $[20,32]$.

In the present study, a close approximation but not significant was found concerning the agreement of the equations using weight, height and gender as variables, 

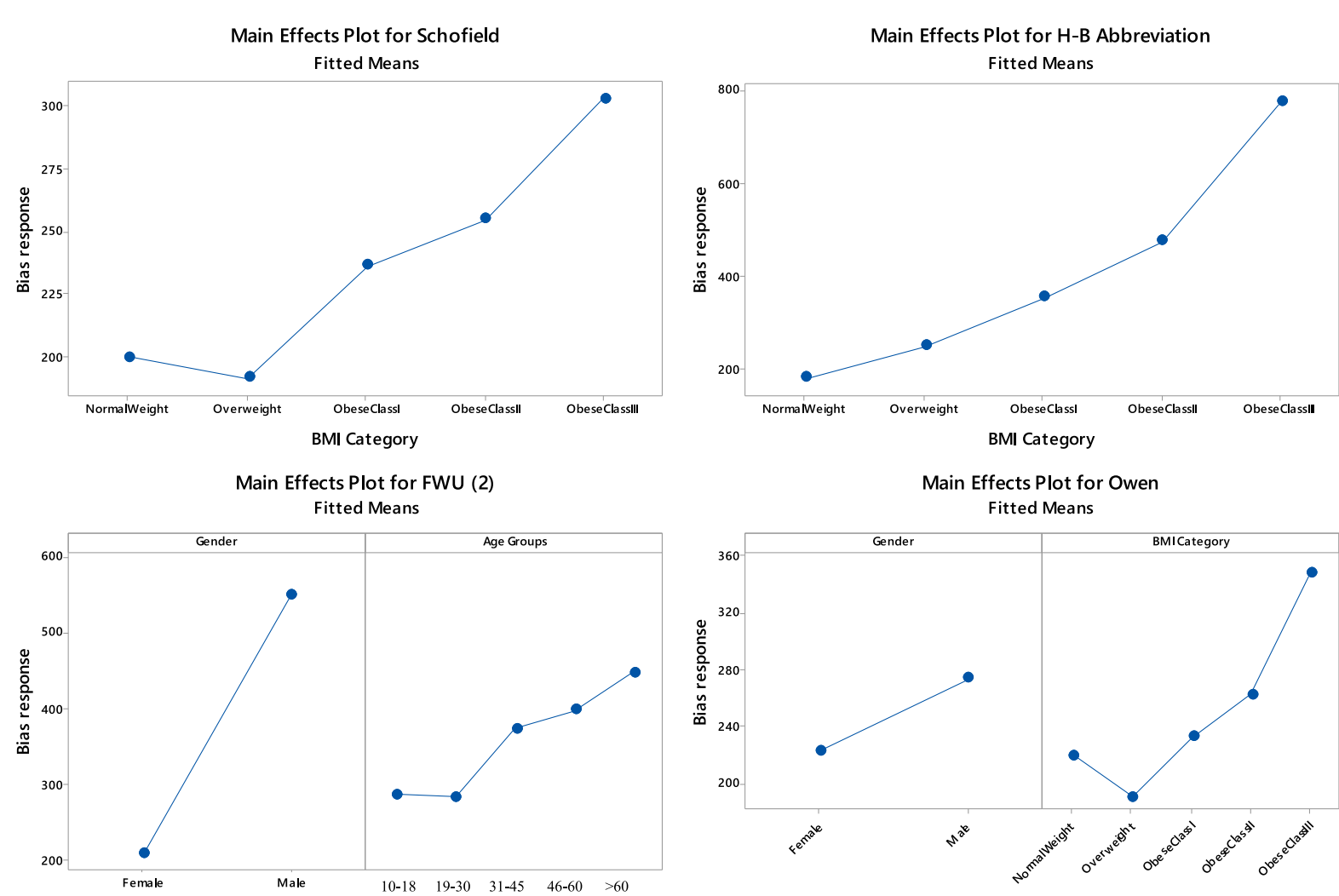

Fig. 1 Main effects plots between transformed absolute bias response and the categorical variables, BMl-classes, Age-groups, Gender

while a limitation by incorporating age groups as an additional factor of co-formulation was recorded. It has been supported in previous studies, that age has been considered as an important factor that increases the predictability of equations [33], further due to modifications of the individual anthropometric features that occur over time such as body composition [32, 34] and the organ and tissue metabolic rate $[35,36]$. In addition, it has been suggested by other studies that the relationship between Free Fat Mass (FFM) and metabolic rate of older people could reflect the level of health of organism, as higher metabolic rates are associated with comorbidity and mortality [34, 37, 38]. Thus, factors correlated with organ and tissue metabolism, which vary depending on
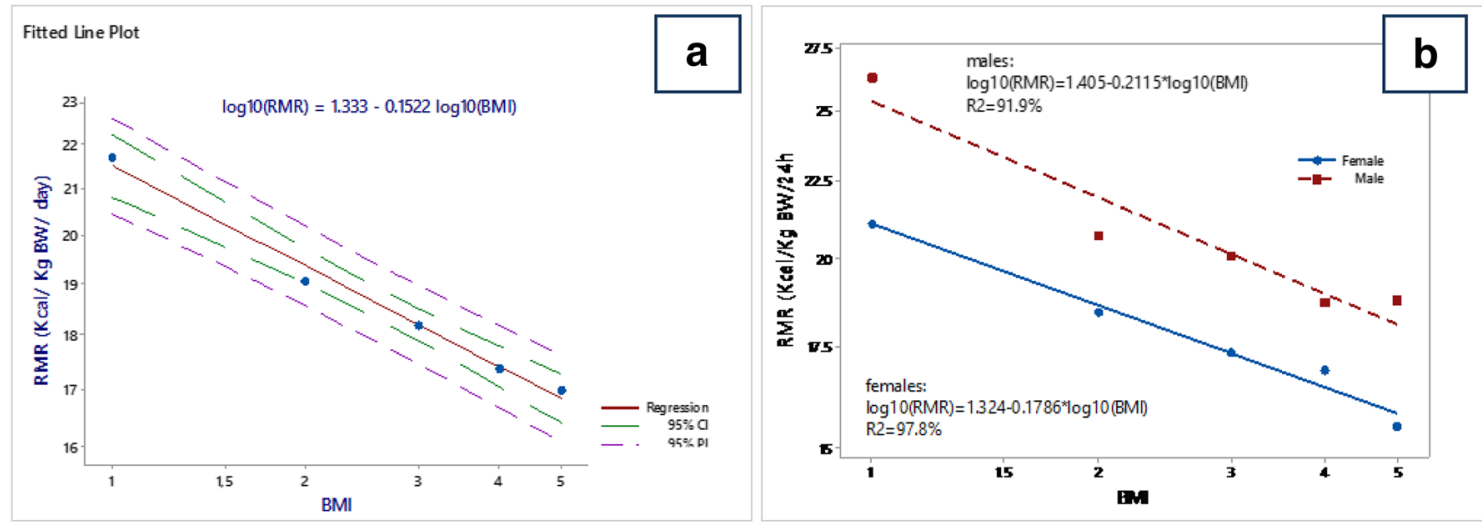

Fig. 2 Log-linear relationship between RMRm and BMI-classes for the whole population (a) and according to gender (b) 
Table 4 RMRm means and their 95\% confidence intervals in the BMl classes (kcal/kg body weight/day)

\begin{tabular}{llll}
\hline BMI classes & Mean & $95 \%$ C.I & N \\
\hline Normal Weight & 21.7 & $20.8-22.6$ & 84 \\
Overweight & 19.1 & $18.3-19.8$ & 123 \\
Obese Class I & 18.2 & $17.3-19.1$ & 77 \\
Obese Class II & 17.4 & $16.3-18.7$ & 37 \\
Obese Class III & 17.0 & $15.9-18.1$ & 59 \\
\hline
\end{tabular}

development, demonstrate a more significant effect on the metabolic capacity of organism [39]. Research also has supported the negative correlation between age and metabolic rate [31].

The results of our study were in good agreement with the findings of research that support the inverse relationship between educational level and BMI, such as NHANES 1999/2000 [40], WHO MONICA project [41], EPIC-PANACEA [42] and many others $[43,44]$. The present study also showed consistently and significantly higher RMR values in people with lower BMI, especially in the normal weight class and these values are decreasing in a log-linear fashion (without taking into consideration the individual body composition analysis), enhancing the results of previous studies, which indicated that people with increased BMI exhibited lower RMR [45]. The proposed logarithmic equation was based on the BMI effect on the RMR responses taken from the IC device. Gender was also incorporated in the equation providing for both sexes reliable estimates (determined coefficients greater than 90\%). Many studies have supported the fact that gender affects metabolic rate [20], due to the different allocation of FM [32] and FFM [32, 46], which also plays an important role in metabolic rate $[47,48]$. It is also supported that hormonal factors lead to additional differences between genders [49]. However, RMR (BMI classes, Wt, and Gender based formulas) equations which have been created are not particularly interesting in terms of practical level of individual calculation, as their reliability is limited to a group level (BMI classes) and are initially used in order to develop a more reliable equation.

Table 5 Stages of evolution of the proposed RMR equation

\begin{tabular}{|c|c|c|c|c|}
\hline \multicolumn{5}{|c|}{ New equations in the initial form } \\
\hline \multicolumn{5}{|c|}{$\log _{10}(\mathrm{RMR})=1.333-0.1522 \log _{10}(\mathrm{BMI})$ or RMR $(\mathrm{Kcal} / \mathbf{2 4} \mathbf{h})=21.53 \times(\mathrm{BMI})^{-0.152}$} \\
\hline \multirow[t]{6}{*}{ RMR equation for both sexes } & \multirow{6}{*}{$\begin{array}{l}\mathbf{R}^{\mathbf{2}}=98.9 \% \\
\mathrm{n}=383 \\
(\text { males }=106, \text { females }=277), \text { age }=10-77 \mathrm{y}\end{array}$} & BMI & \multicolumn{2}{|c|}{ Individual multiplications } \\
\hline & & Normal Weight $=1$ & $(1)^{-0.152}=0.848$ & $(21,53 \times 0,848)=18.26$ \\
\hline & & Overweight $=2$ & $(2)^{-0.152}=1.848$ & $(21.53 \times 1.848)=39.79$ \\
\hline & & Obesity class I = 3 & $(3)^{-0.152}=2.848$ & $(21.53 \times 2.848)=62.32$ \\
\hline & & Obesity class $\|=4$ & $(4)^{-0.152}=3.848$ & $(21.53 \times 3.848)=82.85$ \\
\hline & & Obesity class $\| I=5$ & $(5)^{-0.152}=4.848$ & $(21.53 \times 4.848)=104.38$ \\
\hline \multicolumn{5}{|c|}{$\log 10(\mathbf{R M R})=1.324-0.1786 \times \log 10(\mathrm{BMI})$ or RMR $(\mathbf{K c a l} / \mathbf{K g ~ B W / 2 4} \mathbf{h})=25.41 \times(\mathrm{BMI})^{-0.2115}$} \\
\hline \multirow[t]{6}{*}{ RMR equation for Males } & $\begin{array}{l}\mathbf{R}^{2}=97.8 \% \\
\mathrm{n}=105 \\
\text { males, } \\
\text { Age }=10-77 \text { y }\end{array}$ & BMl & \multicolumn{2}{|c|}{ Individual multiplications } \\
\hline & Normal Weight $=1$ & $(1)^{-0.2115}=0.7885$ & \multicolumn{2}{|c|}{$(25.41 \times 0.7885)=20.3$} \\
\hline & Overweight $=2$ & $(2)^{-0.2115}=1.7885$ & \multicolumn{2}{|c|}{$(25.41 \times 1.7885)=45.50$} \\
\hline & Obesity class $I=3$ & $(3)^{-0.2115}=2.7885$ & \multicolumn{2}{|c|}{$(25.41 \times 2.7885)=70.85$} \\
\hline & Obesity class $\|=4$ & $(4)^{-0.2115}=3.7885$ & \multicolumn{2}{|c|}{$(25.41 \times 3.7885)=96.26$} \\
\hline & Obesity class $I I I=5$ & $(5)^{-0.2115}=4.7885$ & \multicolumn{2}{|c|}{$(25.41 \times 4.7885)=121.67$} \\
\hline \multicolumn{5}{|c|}{$\log _{10}(\mathbf{R M R})=1.405-0.2115 \times \log _{10}(\mathrm{BMI})$ or RMR $(\mathbf{K c a l} / \mathbf{K g ~ B W} / \mathbf{2 4} \mathbf{h})=21.09 \times(\mathrm{BMI})^{-0.1786}$} \\
\hline \multirow[t]{6}{*}{ RMR equation for Females } & $\begin{array}{l}\mathbf{R}^{\mathbf{2}}=91.9 \% \\
\mathrm{n}=278 \\
\text { females, } \\
\text { Age }=10-77 \text { y }\end{array}$ & BMl & \multicolumn{2}{|c|}{ Individual multiplications } \\
\hline & Normal Weight $=1$ & $(1)^{-0.1786}=0.8214$ & \multicolumn{2}{|c|}{$(21.09 \times 0.8214)=17.32$} \\
\hline & Overweight $=2$ & $(2)^{-0.1786}=1.8214$ & \multicolumn{2}{|c|}{$(21.09 \times 1.8214)=38.41$} \\
\hline & Obesity class I = 3 & (3) $)^{-0.1786}=2.8214$ & \multicolumn{2}{|c|}{$(21.09 \times 2.8214)=59.50$} \\
\hline & Obesity class $\|=4$ & (4) $)^{-0.1786}=3.8214$ & \multicolumn{2}{|c|}{$(21.09 \times 3.8214)=80.59$} \\
\hline & Obesity class $\| I=5$ & $(5)^{-0.1786}=4.8214$ & \multicolumn{2}{|c|}{$(21.09 \times 4.8214)=101.68$} \\
\hline
\end{tabular}


The data analysis of this study is going to be rescheduled in order to use a different statistic methodology based on the Bland-Altman graphical technique for the identification of the systematic difference between RMRm and RMRe. There will also be an effort to create a new equation which will approach RMRm at an individual calculation level.

\section{Limitations}

Fitmate portable calorimetry device is used in the present study and has been proven through numerous studies that it generally provides a robust RMR assessment [50]. However, to avoid measurement errors, compliance with the protocols should be ensured [1] Best practices prior to measurement include: the good health of the supervised person and the appropriate period of fasting, nicotine and caffeine abstinence and restriction of physical activity. During the measurement, best practices concern: the assurance of the appropriate environmental conditions of the test area (temperature, lack of noise), appropriate body position, rest period before the start of the measurement, time of day, but also the day is selected to be examined. From the use of the device, the causes that may alter the measurement are mainly: the duration of the measurement, the rejection time, the breathing rate (RQ) (which is set to 0.85 by default or can be set by the user and the type of gas collection devices (facemask, mouthpiece, canopy) [1].

It should be clarified that the use of silicone facemask used in the study lags behind the use of canopy. Moreover, possible oxygen losses, which may occur during the measurement, should be mentioned, if the auditee has a beard.

In addition, the RMR measurement system used for study purposes lags behind other more improved systems that allow a more accurate measurement of REE and respiratory quotient (RQ) by measuring $\mathrm{VO} 2$ (and carbon dioxide) and carbon dioxide production (VCO2) along with other respiratory parameters, as well as by calculation of the metabolic.

Furthermore, the RMR measurement period (time of year) was not recorded since variations in metabolic rate due to seasonal variations have not been reported in many studies, regarding people who live in a modern western environment and are not exposed to a cold climate. Finally, the absence of the thermogenic effect of brown adipose tissue during seasonal variations has yet not been reported and needs further investigation [51].

\section{Conclusion}

The present study provides valuable information on the necessity of BMI consideration in the prediction equations of RMR, so allowing a better performance and a closer measuring agreement with various devices of metabolic interest. Additionally, our findings promote a better understanding of the measured parameters by increasing the predictive reliability of equations. The results confirm previous reports for the well-established inverse relationship between BMI and RMR and also the relatively higher calorific burden in the lower BMI classes which are strongly affiliated with the tertiary education level. Apart from BMI classes, variables such as Age Group and Gender play significant role on the absolute bias response of some RMR equations and need further investigation of their effects.

\section{Additional files}

Additional file 1: Table S1 AF. Physical characteristics of the subjects as cross-tabulated by BMI classes, Age group and Gender. (DOCX 16 kb)

Additional file 2: Table S2 AF. Equations for Estimating Energy Expenditure. (DOCX $21 \mathrm{~kb})$

Additional file 3: Table S3 AF. Tabulated statistics between BMI classes and gender, age groups and education level. (DOCX 19 kb)

\section{Abbreviations \\ BMI: Body mass index; BMR: Basal metabolic rate; BMRe: Estimated BMR; BMRm: BMR measured; BW: Body weight; EE: Energy expenditure; FFM: Fat- free mass; FM: Fat mass; F-W-U: FAO-WHO-UNU; H-B: Harris-Benedict; IC: Indirect calorimetry; REE: Resting energy expenditure; RMR: Resting metabolic rate; RMRe: Estimated RMR; RMRm: Measured REE; TEE: Total energy expenditure; TEF: Thermic effect of food}

\section{Funding}

This research did not receive any specific grant from funding agencies in the public, commercial, or not-for-profit sectors.

Availability of data and materials

Please contact author for data requests.

\section{Authors' contributions}

EP contributed to conception/design of the research; to acquisition, analysis, or interpretation of the data; drafted the manuscript; critically revised the manuscript; agree to be fully accountable for ensuring the integrity and accuracy of the work. DP contributed to conception/design of the research; to acquisition, analysis, or interpretation of the data; drafted the manuscript; agree to be fully accountable for ensuring the integrity and accuracy of the work. MT contributed to conception/design of the research; contributed to acquisition, analysis, or interpretation of the data; critically revised the manuscript; agree to be fully accountable for ensuring the integrity and accuracy of the work. NT, agree to be fully accountable for ensuring the integrity and accuracy of the work. AP, contributed to acquisition, analysis, or interpretation of the data; critically revised the manuscript; agree to be fully accountable for ensuring the integrity and accuracy of the work.AF,

contributed to conception/design of the research; contributed to acquisition, analysis, or interpretation of the data; critically revised the manuscript; agree to be fully accountable for ensuring the integrity and accuracy of the work. GK, agree to be fully accountable for ensuring the integrity and accuracy of the work. CG, contributed to conception/design of the research; contributed to acquisition, analysis, or interpretation of the data; critically revised the manuscript; agree to be fully accountable for ensuring the integrity and accuracy of the work. All authors read and approved the final manuscript.

Ethics approval and consent to participate Not applicable. 


\section{Competing interests}

The authors declare that they have no competing interests.

\section{Publisher's Note}

Springer Nature remains neutral with regard to jurisdictional claims in published maps and institutional affiliations.

\section{Author details}

'Department of Food Science and Nutrition, University of Aegean, Mitropoliti loakim 2, Myrina, Lemnos, 81440 Athens, Greece. ${ }^{2}$ Department of Food Technology, Technological Educational Institute, 57400 Thessaloniki, Greece. ${ }^{3}$ Department of Radiotherapy, School of Health Sciences, Faculty of Medicine, University of Thessaly, 41110 Biopolis, Larissa, Greece. ${ }^{4}$ Department of Oncology, Veterans Hospital (NIMTS), 10 Monis Petraki, 11521 Athens, Greece. ${ }^{5}$ Surgery Clinic, School of Health Sciences, Faculty of Medicine, University of Thessaly, 41110 Larissa, Greece.

\section{Received: 13 October 2017 Accepted: 18 May 2018}

\section{Published online: 15 June 2018}

\section{References}

1. Compher C, Frankenfield D, Keim N, Roth-Yousey L. Evidence analysis working group. Best practice methods to apply to measurement of resting metabolic rate in adults: a systematic review. J Am Diet Assoc. 2006:106: 881-903.

2. Gibney JM, Lanham-new AS, Cassidy A, Vorster HH. Introduction to human nutrition, 2nd ed. ISBN: 978-1-405-16807-6. United Kingdom: Wiley; 2009.

3. ASPEN. American Society for Parenteral and Enteral Nutrition The science and practice of nutritional support. USA: Kendal/Hunt Publishing Company; 2001. p. 118-23.

4. Ravussin E, Bogardus C. A brief overview of human energy metabolism and its relationship to essential obesity. Am J Clin Nutr. 1992;55:242S-5S.

5. Barasi EM. Nutrition at a glance. 1st ed. ISBN 10: 1405134879. Dunfermline: Wiley; 2007.

6. Institute of Medicine, Food and nutrition board. Dietary reference intakes for energy, carbohydrate, fiber, fat, fatty acids, cholesterol, protein and amino acids.Washington, DC: the National Academies Press; 2002.

7. Mahan LK, Raymond L. Krause's Food \& the Nutrition Care Process. 14th ed Canada: Elsevier; 2017.

8. McArdle WD, Katch Fl, Katch VL. Sports \& exercise nutrition. 4th ed. Philadelphia: Lippincott: Williams \& Wilkins; 2012

9. Gropper SS, Smith LJ, Groff LJ. Advanced nutrition and human metabolism. 6th ed. USA: Thomson Wadsworth; 2012.

10. Matarese LE. Indirect calorimetry: technical aspects. J Am Diet Assoc. 1997; 97S:154-60. 9336580

11. Lupinsky L, Singer $P$, Theilla M, Grinev M, Hirsh R, Lev S, et al. Comparison between two metabolic monitors in the measurement of resting energy expenditure and oxygen consumption in diabetic and non-diabetic ambulatory and hospitalized patients. Nutrition. 2015;31:176-9. https://doi. org/10.1016/j.nut.2014.07.013.

12. Det $V$, Salacinski AJ, Broeder CE. A comparison of COSMED metabolic systems for the determination of resting metabolic rate. Res Sports Med. 2013;21:187-94. https://doi.org/10.1080/15438627.2012.757226.

13. Lee JM, Bassett DR Jr, Thompson DL, Fitzhugh EC. Validation of the Cosmed Fitmate for prediction of maximal oxygen consumption. J Strength Cond Res. 2011;25:2573-9. https://doi.org/10.1519/JSC.0b013e3181fc5c48.

14. Shaneshin M, Jessri M, Rashidkhani B. Validity of energy intake reports in relation to dietary patterns. J Health Popul Nutr. 2014;32:36-45.

15. El Ghoch M, Alberti M, Capelli C, Calugi S, Dalle Grave R. Resting energy expenditure in anorexia nervosa: measured versus estimated. J Nutr Metab 2012; Article ID 652932, 6 pag. doi: https://doi.org/10.1155/2012/652932.

16. Namazi N, Aliasgharzadeh S, Mahdavi R, Kolahdooz F. Accuracy of the common predictive equations for estimating resting energy expenditure among normal and overweight girl university students. J Am Coll Nutr. 2016:35:136-42. https://doi.org/10.1080/07315724.2014.938280.

17. Cheng HL, Amatoury M, Steinbeck K. Energy expenditure and intake during puberty in healthy nonobese adolescents: a systematic review. Am J Clin Nutr. 2016;104:1061-74.

18. Patil SR, Bharadwaj J. Development of new equations for basal metabolic rate for adolescent student Indian population. J Postgrad Med. 2013:59:25-9. https:/doi.org/10.4103/0022-3859.109491.
19. Gurven MD, Trumble BC, Stieglitz J, Yetish G, Cummings D, Blackwell AD, et al. High resting metabolic rate among Amazonian forager-horticulturalists experiencing high pathogen burden. Am J Phys Anthropol. 2016;161:414-25. https://doi.org/10.1002/ajpa.23040.

20. Herrmann DS, McMurray GR, Kim Y, Willis AE, Kang M, McCurdy T. The influence of physical characteristics on the resting energy expenditure of youth: a meta-analysis. Am J Hum Biol. 2016;29:1-14. https://doi.org/10. 1002/ajhb.22944. PubMed: 27901289.

21. Harris JA, Benedict FG. A biometric study of human basal metabolism. Proc Natl Acad Sci U S A. 1918;4:370-3.

22. Roza MA, Shizgal MH. The Harris Benedict equation reevaluated. Am J Clin Nutr. 1984;40:168-82.

23. Manual of Clinical Dietetics. Edition 6, by American Dietetic Association, South Suburban Dietetic Association Staff, Dietitians of Canada Staff, Dietitians of Canada, Staff of Dietitians of Canada. ISBN-10:0880911875. USA American Dietetic Association; 2000.

24. Schofield WN. Predicting basal metabolic rate, new standards and review of previous work. Hum Nutr Clin Nutr. 1985;39:5-41.

25. Owen OE. Resting metabolic requirements of men and women. Mayo Clin Proc. 1988;63:503-10.

26. FAO/NHO/UNU Expert Panel. Energy and protein requirements. In: Report of a Joint FAO/WHO/UNU Expert Consultation; World Health Organ Tech Rep Ser; 1985. p. 1-206.

27. Mifflin MD, St Jeor ST, Hill LA, Scott BJ, Daugherty SA, Koh YO. A new predictive equation for resting energy expenditure in healthy individuals. Am J Clin Nutr. 1990;51:241-7.

28. Harrington ME., St. Jeor ST., Silverstein LJ. Predicting resting energy expenditure from body mass index: practical applications and limitations: annual conference proceedings, North American Association for the Study of Obesity. J Obesity Res 1997;5 (Suppl.):AO66.

29. Michels MW, Grootendorst CD, Verduijn M, Elliott GE, Dekker WF, Krediet TR Performance of the Cockcroft-Gault, MDRD, and New CKD-EPI Formulas in Relation to GFR, Age, and body size. Clin J Am Soc Nephrol. 2010;5:1003-9. https://doi.org/10.2215/CJN.06870909.

30. Lee M, Kwon DY, Kim MS, Choi CR, Park MY, Kim AJ. Genome-wide association study for the interaction between BMR and BMI in obese Korean women including overweight. Nutr Res Pract. 2016;10:115-24. https://doi. org/10.4162/nrp.2016.10.1.115.

31. Jin P, Park HJ, So YW. Relationship between bioelectrical impedance-derived estimates of basal metabolic rate and body composition parameters in female Korean college students. S Afr J Res Sport Phys Educ Recreation. 2015;37:87-98.

32. Lazzer S, Bedogni G, Lafortuna LC, Marazzi N, Busti C, Galli R, et al. Relationship between basal metabolic rate, gender, age, and body composition in 8,780 white obese subjects. Obesity. 2010;18:71-8. https:// doi.org/10.1038/oby.2009.162.

33. Müller MJ, Bosy-Westphal A, Klaus S, Kreymann G, Luhrmann PM, Neuhauser-Berthold $M$, et al. World health organization equations have shortcomings for predicting resting energy expenditure in persons from a modern, affluent population: generation of a new reference standard from a retrospective analysis of a german database of resting energy expenditure. Am J Clin Nutr. 2004;80:1379-90.

34. Geisler C, Braun W, Pourhassan M, Schweitzer L, Glüer CC, Bosy-Westphal A., et al. Age-dependent changes in resting energy expenditure (REE): insights from detailed body composition analysis in normal and overweight healthy Caucasians. Nutrients 2016; 1:8. https://doi.org/10. 3390/nu8060322

35. Gbenga, Boluwaji Jaiyesimi. The assessment of anthropometry and selected body composition parameters as predictor of basal metabolic rate of female university undergraduates. J Pure Appl Sci 2015; V (1): 26-30 ISSN: 2278-8779

36. Wang Z, Ying Z, Bosy-Westphal A, Zhang J, Schautz B, Later W, et al. Specific metabolic rates of major organs and tissues across adulthood: evaluation by mechanistic model of resting energy expenditure. Am J Clin Nutr. 2010:92: 1369-77. https://doi.org/10.3945/ajcn.2010.29885.

37. Ruggiero C, Metter EJ, Melenovsky V, Cherubini A, Najjar SS, Ble A, et al. High basal metabolic rate is a risk factor for mortality: the Baltimore longitudinal study of aging. J Gerontol A Biol Sci Med Sci. 2008;63:698-706. PMID:18693224

38. Fabbri E, An Y, Schrack JA, Gonzalez-Freire M, Zoli M, Simonsick EM, et al. Energy metabolism and the burden of multimorbidity in older adults: 
results from the Baltimore longitudinal study of aging. J Gerontol Ser A Biol Sci Med Sci. 2015;70:1297-303. https://doi.org/10.1093/gerona/glu209.

39. Gallagher D, Belmonte D, Deurenberg P, Wang Z, Krasnow N, Pi-Sunyer FX, et al. Organ-tissue mass measurement allows modeling of REE and metabolically active tissue mass. Am J Physiol Endocrinol Metab. 1998;275: E249-58.

40. Zhang Q, Wang Y. Trends in the association between obesity and socioeconomic status in U.S. adults: 1971 to 2000. Obesity Res. 2004;12: 1622-32. https://doi.org/10.1038/oby.2004.202.

41. Molarius A, Seidell JC, Sans S, Tuomilehto J, Kuulasmaa K. Educational level, relative body weight, and changes in their association over 10 years: an international perspective from the WHO MONICA project. Am J Public Health. 2000;90:1260-8.

42. Hermann S, Rohrmann S, Linseisen J, May MA, Kunst A, Besson H, et al. The association of education with body mass index and waist circumference in the EPIC-PANACEA study. BMC Public Health. 2011;11:169. https://doi.org/10. 1186/1471-2458-11-169.

43. Maddah M, Eshraghian RM, Djazayery A, Mirdamadi R. Association of body mass index with educational level in Iranian men and women. Eur J Clin Nutr. 2003;57:819-23. https://doi.org/10.1038/sj.ejcn.1601615.

44. Van Lenthe FJ, Droomers M, Schrijvers CT, Mackenbach JP. Sociodemographic variables and 6 year change in body mass index: longitudinal results from the GLOBE study. Int J Obes Relat Metab Disord. 2000;24: 1077-84.

45. Rosales-Velderrain A, Goldberg RF, Ames GE, Stone RL, Lynch SA, Bowers SP. Hypometabolizers: characteristics of obese patients with abnormally low resting energy expenditure. Am Surg. 2014;80:290-4.

46. Malina RM, Bouchard C, Bar-Or O. Growth, maturation, and physical activity. 2nd ed. Champaign, IL: Human kinetics; 2004.

47. Meeuwsen S, Horgan G, Elia M. The relationship between BMl and percent body fat, measured by bioelectrical impedance, in a large adult sample is curvilinear and influenced by age and sex. Clin Nutr. 2010;29:560-6. https:// doi.org/10.1016/j.clnu.2009.12.011.

48. Laforgia J, van der Ploeg GE, Withers RT, Gunn SM, Brooks A, Chatterton B. Impact of indexing resting metabolic rate against fat-free mass determined by different body composition models. Eur J Clin Nutr. 2004;58:1132-41. https://doi.org/10.1038/sj.ejcn.1601941.

49. Ho KY, Evans WS, Blizzard RM, Veldhuis JD, Merriam GR, Somojlik E, et al. Effects of sex and age on the 24-hour profile of growth hormone secretion in man: importance of endogenous estradiol concentrations. J Clin Endocrinol Metab. 1987;64:51-8. https://doi.org/10.1210/jcem-64-1-51.

50. Pavlidou E, Petridis D, Fasoulas A, Giaginis C. Current clinical status on the estimation of energy requirement: searching for an identical equation to predict basal energy expenditure in multiple populations. Curr Nutr Food Sci. 2018;14:1-11.

51. Anthanont P, Levine AJ, McCrady-Spitzer KS, Jensen DM. Lack of seasonal differences in basal metabolic rate in humans: a cross-sectional study. Horm Metab Res. 2017;49:30-5. https://doi.org/10.1055/s-0042-107793.

\section{Ready to submit your research? Choose BMC and benefit from:}

- fast, convenient online submission

- thorough peer review by experienced researchers in your field

- rapid publication on acceptance

- support for research data, including large and complex data types

- gold Open Access which fosters wider collaboration and increased citations

- maximum visibility for your research: over $100 \mathrm{M}$ website views per year

At BMC, research is always in progress.

Learn more biomedcentral.com/submissions 